\title{
Sujeto, comunidad y utopía
}

\author{
JUAN JOSÉ TAMAYO-ACOSTA \\ Universidad Carlos III de Madrid
}

RESUMEN. La razón moderna europea surge y se desarrolla bajo el signo de la subjetividad. El sujeto constituye el centro y el horizonte del pensamiento de la modernidad. La historia de dicho pensamiento es un proceso de construcción, deconstrucción y reconstrucción del sujeto. El presente estudio tiene como objetivo seguir el tortuoso viaje de la subjetividad en tres direcciones no siempre convergentes $-\mathrm{y}$, a veces, claramente divergentes-: del descubrimiento del individuo como sujeto al individualismo; de la afirmación de la subjetividad a la conciencia utópica; de la persona a la comunidad.

\begin{abstract}
It can be affirmed that european modern reason arose marked by subjectivity. And so it has been developed in the same spirit. The thought of the modernity has in the subjectivity its core and its focus. For this reason the history of that thought is a process of construction, deconstruction and reconstruction of the subject. The issue of this article is the exposure of the three lines - sometimes opposite lines - marked by the travel of subjectivit: (a) the way from the discovery of individual as a subject to the individualism, (b) the way from the claim of subjectivity to the utopic conscience, (c) and the way from person to community.
\end{abstract}

\section{DEL INDIVIDUO AL INDIVIDUALISMO}

\section{El giro antropológico}

Una de las principales aportaciones de la filosofía moderna europea ha sido el descubrimiento de la subjetividad, el reconocimiento de la persona como sujeto y la valoración del ser humano como fin en sí mismo. El ser humano se auto-identifica como sujeto con identidad propia, no reductible a Dios, ni a la naturaleza, ni a otros seres humanos. Se concibe como libre, autónomo, dueño de su futuro, creador y responsable único en la construcción de la historia y de sí mismo. El sujeto emerge, según A. Touraine, «como libertad y como creación» ${ }^{1}$. El ser humano se encuentra a solas consigo mismo, sin dioses ni demonios, sin padre divino que le proteja en las dificultades o le saque de apuros cuando el agua le llega al cuello. La historia de la salvación trascendente da paso a la historia de la emancipación histórica de mujeres y hombres. El ser humano deja de creer que «sólo Dios puede salvarle». Se encuentra, así, ante una responsabilidad histórica que no puede delegar.

\footnotetext{
'A. Touraine, Crítica de la modernidad, Madrid, Temas de Hoy, 1993, p. 265.
} 
En la sociedad moderna, el fundamento de los valores morales no se encuentra ya en Dios, sino en el ser humano que deviene sujeto y se constituye en principio moral autónomo. Hay un salto auténticamente revolucionario en el terreno del pensamiento: se pasa de un sistema sin sujeto a un mundo con sujeto. Ello tendrá posteriormente su traducción política en el reconocimiento y el ejercicio de las libertades públicas.

Muy al principio de la Edad Moderna, Pico della Mirandola anunciaba ya el giro antropológico que estamos describiendo y que iba a ser el santo y seña del Renacimiento e iba a tener su fundamentación filosófica y política en la Ilustración y la Revolución Francesa respectivamente. He aquí su lúcido testimonio, que data de 1492: «Dios se complace creando al hombre como un ser que no tiene ninguna imagen claramente discernible. Lo puso en el medio del mundo y le dijo: No te hemos dado ningún lugar determinado para habitar, ningún rostro propio, ninguna dote especial... Para los demás seres, su naturaleza está determinada por las leyes que les hemos prescrito y se mantienen en los límites. Tú, en cambio, no tienes una sola barrera insuperable, sino que tú mismo has de determinar tu propia naturaleza según tu libre albedrío, en cuyas manos yo he puesto tu destino. Te hemos creado como un ser que no es ni celestial ni terrenal; ni mortal ni inmortal. Antes bien, tú, como escultor y poeta de ti mismo plenamente libre y que trabaja para su propio honor, te darás la forma en que tú mismo quieras vivir» ${ }^{2}$.

La antropología no es una disciplina más de la filosofía, sino que se constituye en disposición fundamental que ordena y guía el pensamiento filosófico moderno. Ello se aprecia con total nitidez cuando Kant añade a sus tres preguntas: «qué puedo saber, qué debo hacer y qué me cabe esperar», una cuarta: qué es el ser humano.

Pero la filosofía de la subjetividad va a acentuar la dimensión interna del ser humano sobre la externa. Con la distinción de Descartes entre res cogitans y res extensa, se inicia una corriente filosófica dualista que abrirá una sima cada vez más honda entre lo interior y lo exterior, entre el individuo y la sociedad. El individuo es pensado fuera de la sociedad, y ésta fuera de los individuos. El ser humano es pensado como mónada (Leibniz). La autonomía del sujeto se torna clausura sobre sí mismo para así protegerse del mundo exterior.

Aristóteles había definido al ser humano bajo una doble caracterización, no excluyente, sino complementaria: como «animal político» (zóon politikón) y como «animal que tiene el logos» (zóon lógon éjon). Sin embargo, la modernidad disocia una de otra. El logos, observa atinadamente C. París, es entendido en cuanto «expresión de nuestra racionalidad o del uso de nuestra palabra, independientemente de la dimensión ciudadana (política)» ${ }^{3}$. Hay un confi-

${ }^{2}$ N. Pico della Mirandola, De dignitate hominis, Florencia, 1492.

${ }^{3}$ C. París, El animal cultural. Biología y cultura en la realidad humana, Barcelona, Crítica, 1994, p. 22. Esta idea es desarrollada en el sugerente apartado que lleva por título «El "logos" 
namiento del logos en la interioridad y un alejamiento de la ciudad. «En semejante intemperie, el hombre se encuentra como un personaje extraño, sin sociedad, sin ley, sin hogar, según los términos homéricos que recoge Aristóteles. El hombre comparable a un pájaro solitario, a una pieza suelta en un juego de damas, se hace pendenciero, amigo de la guerra, afirma el Estagirita ${ }^{4}$. Descartes considera al ser humano como un yo racional, como pensamiento puro no mediado por determinación espacial o material alguna. El pensamiento puro en que se conceptualiza el ser humano huye del cuerpo y de la ciudad y se queda solo ante sí.

\section{El utilitarismo}

Así se desemboca en el individualismo, característica de las corrientes utilitaristas y liberales. El utilitarismo de Jeremy Bentham (1748-1832) concibe la sociedad como un agregado de átomos individuales. El primer principio de la ética utilitarista es el interés: el ser humano actúa movido por su propio interés con el deseo de combatir el dolor y de lograr el máximo de placer. El segundo principio es la felicidad: el ser humano actúa movido por el deseo de conseguir el máximo de felicidad. Pero ambos principios no se quedan, dirá Bentham, en el plano individual; deben extenderse a la sociedad y producir sus efectos en el mayor número de individuos. En otras palabras: la suma de intereses individuales da como resultado el interés general; de la suma de las «felicidades» de cada uno resulta la felicidad del conjunto.

Aun reconociendo las aportaciones de esta teoría, creo pueden hacérsele tres objeciones. Por una parte, la realidad humana y social desmiente la relación simétrica que Bentham establece entre intereses individuales y colectivos: la suma de los intereses individuales no da como resultado el bienestar general; el interés individual no trasciende al individuo. Por otra, el utilitarismo no se rige por criterios de igualdad y justicia. En tercer lugar, la razón del utilitarismo no es una razón integradora, sino calculadora; su principal referente no es precisamente un mundo más humano regido por el principio de la fraternidad, sino un mundo mercantil, regido por las reglas de juego del beneficio particular.

y la ciudad», pp. 22-24. Me he ocupado de este libro en La cultura como desarrollo de la biologia: El Ciervo, 531 (junio 1995), pp. 33-34.

${ }^{4}$ Ibid. 


\section{Individualismo liberal}

La historia del pensamiento político liberal es la historia de las relaciones entre individuo, sociedad y Estado, y de la demarcación de los respectivos ámbitos de actuación. El individualismo se encuentra en la base de la tradición ilustrado-liberal. «El culto al individuo asevera C. Molina Petit- es uno de los elementos esenciales que consagra el liberalismo a partir de la tradición ilustrada. El individualismo se afirma frente a la colectividad y al Estado» ${ }^{5}$. La teoría liberal defiende la libertad individual, acentúa la independencia del ser humano y minusvalora la sociabilidad; subraya la autosuficiencia y devalúa la interdependencia. De nuevo aparece el ser humano aislado, alejado de la comunidad.

Pero hay un hecho que la teoría ilustrada-liberal no puede esquivar: los individuos viven en sociedad, en grupos humanos. La pregunta no puede reprimirse: ¿Cómo son las relaciones de los individuos dentro de los grupos? El liberalismo extremo responde que son relaciones artificiales, interesadas, de contigüidad, de asociación externa, de interdependencia mecánica. Lo que cada uno pretende es la defensa de sus intereses. En esta teoría no se tienen en cuenta las bases profundas en que se sustentan la cohesión e interacción sociales.

Veamos un par de ejemplos típicos de la mentalidad individualista liberal: Th. Hobbes y J. Stuart Mill.

Thomas Hobbes (1588-1679) es un cualificado representante del individualismo ético. La idea extendida entre los científicos de su tiempo era el atomismo mecanicista, según el cual todo cuerpo material es una suma de átomos independientes entre sí. Hobbes traslada esta idea científica al ámbito de la sociedad. El cuerpo social es un agregado de individuos que buscan su propio interés. El ser humano se rige en su vida y sus actuaciones por impulsos egoístas, que le llevan a entrar en conflicto con los demás seres humanos. «Si dos individuos desean lo mismo y no pueden poseerlo junto - afirma-, se convierten en enemigos y se esfuerzan por destruir o someter al otro» ${ }^{6}$. La lucha de todos contra todos es tan permanente y feroz, cree Hobbes, que, a la hora de garantizar la seguridad total al individuo, los pactos que no recurren a la espada se quedan en meras palabras no vinculantes. La naturaleza del ser humano es antisocial.

John Stuart Mill (1806-1873) se mueve en el horizonte del utilitarismo de Bentham, pero críticamente. A éste le matiza que la búsqueda y consecución : de la propia felicidad y de los propios intereses no desembocan, de facto, en la felicidad y el interés generales. Lo que generan es injusticia.

${ }^{5}$ C. Molina Petit, Dialéctica feminista de la llustración, Barcelona, Anthropos, 1994, p. 161. Esta obra constituye una de las aportaciones más relevantes de la filosofía feminista en nuestro país.

${ }^{6}$ Th. Hobbes, Leviatán, citado en M. Rader, Ética y democracia, Estella (Navarra), Verbo Divino, 1975, p. 162. 
Stuart Mill distingue dos planos en la vida humana: el interno y el social. La esfera interna comprende el mundo propio del individuo: sentimientos, deseos, pensamientos, etc.; es el mundo de la conciencia personal donde nadie puede penetrar, ni inmiscuirse: ni el poder político, ni otros individuos.

La libertad del individuo es omnímoda y no puede ser limitada ni por nada ni por nadie. El único dique son «los derechos e intereses de los demás». «El hombre con carácter extremadamente individualizado, distinto, independiente y autosuficiente es el verdadero individuo para Mill», resume C. Molina Petit $^{7}$.

\section{Liberalismo económico}

El individualismo liberal desde el punto de vista filosófico y político desemboca derechamente en el individualismo económico. Los fisiócratas aplican las leyes de la naturaleza al orden social y excluyen toda intervención del Estado en la actividad económica; ésta se auto-regula y auto-equilibra. El criterio que rige la actividad económica es el interés personal; pero al proseguir el interés personal, se promueve «necesariamente» el bien común. Hay «una mano invisible» que armoniza el beneficio individual y el beneficio del conjunto social. He aquí un texto paradigmático de Adam Smith al respecto: «Todo individuo se esfuerza constantemente por hallar el empleo más ventajoso del capital de que puede disponer. Se trata, por supuesto, de su ventaja personal, y no de la social. Pero la consideración de su provecho individual le conduce, de un modo natural o mejor necesario, a perseguir el empleo que resulte más beneficioso de la sociedad... Con frecuencia, buscando su propio interés, promueve el de la sociedad de un modo más eficaz que cuando intenta potenciarlo de una manera consciente y deliberada» ${ }^{8}$.

De nuevo reitera la misma idea Smith relacionando libertad, interés propio, competitividad y justicia en estos términos: «Debe permitirse a todo hombre, en la medida en que no viole las leyes de la justicia, que persiga con toda libertad su propio interés y que compita con otros seres humanos u órdenes de seres humanos en el campo de la industria y del capital» ${ }^{9}$.

Otros representantes del liberalismo económico se olvidan de la justicia en las relaciones económicas y no ponen límite alguno a la competitividad o competencia. Es el planteamiento de F. Bastiat, para quien «competencia es libertad»y «libertad es competencia».

Llegamos así a la categoría de competencia que, para el liberalismo económico clásico, constituye la clave de la auto-regulación y del auto-equilibrio

\footnotetext{
${ }^{7}$ Op. cit., p. 163.

${ }^{8}$ A. Smith, The Walth of Nations, Nueva York, Modern Library, 1937, pp. 421-423; citado en M. Rader, op. cit., p. 321.

${ }^{9}$ Ibid., p. 651; cita en M. Rader, pp. 321-322.
} 
y es el puente de unión entre los intereses individuales de los actores económicos y el bien social. Stuart Mill considera negativa cualquier restricción de la competencia. Poner límites a ésta puede perjudicar por algún tiempo a los trabajadores, matiza, pero «es siempre un bien definitivo» ${ }^{10}$. La competencia defiende y refuerza la libertad económica individual y la igualdad de oportunidades en el terreno mercantil.

Una de las críticas más severas y certeras al liberalismo en sus diferentes vertientes viene de R. P. Wollf, en su obra La pobreza del liberalismo, donde llama la atención sobre la ausencia del sentido comunitario en dicho sistema. El individuo del liberalismo es una especie de Robinson Crusoe, cuya naturaleza nada tiene de social. La relación contractual no responde al bien común, sino a la satisfacción de las propias necesidades. La incapacidad para hacerse cargo de la idea de comunidad social, afirma J. Muguerza citando a R. P. Wolff, es el mejor exponente de la «miseria del liberalismo» ${ }^{11}$.

El individualismo liberal elimina la comunidad tradicional, al romper los lazos que le servían de cohesión. Pero no es capaz de facilitar el camino para construir la comunidad de iguales que propiciaron algunas corrientes utópicas de la modernidad.

\section{El neo-liberalismo}

El neo-liberalismo actual constituye una reencarnación del liberalismo clásico, pero sin las iniciales señas humanistas de éste y con una tendencia a radicalizar el individualismo hasta extremos insospechados. El modelo neo-liberal tiene como bases estas cuatro: la libertad individual como valor absoluto, la libre iniciativa como despliegue de la libertad individual, la privacidad como espacio privilegiado de realización humana y la competitividad orientada al triunfo y a la superación individuales. La insensibilidad ante las abismales diferencias sociales y económicas es una de las actitudes más notorias del modelo neo-liberal, que elimina de su lógica individualista valores como el compartir, la participación, la gratuidad y la solidaridad. Las relaciones humanas se rigen por el beneficio y el interés propios.

Nada escapa a la influencia del liberalismo. Su jerarquía de valores no se queda en la esfera económica, sino que penetra en la órbita de la vida privada, familiar y lúdica; ésta comienza a guiarse por el propio interés, el carácter venal de las cosas y la utilidad de las personas.

En su versión económica, el neoliberalismo tiene características peculiares que conviene subrayar. Da prioridad a los agentes individuales en las actuaciones económicas sobre los agentes colectivos: sindicatos, organizaciones no gubernamentales, gobiernos, etc. Consecuentemente con ello pone el acento en la

\footnotetext{
${ }^{10}$ J. Stuart Mill, Principios de política económica, libro IV, cap. VII, par. 7.

${ }^{11}$ J. Muguerza, Desde la perplejidad, México-Madrid, FCE, 1990, p. 259.
} 
libertad de actuación de los agentes económicos individuales y apenas se ocupa del control de dichas actuaciones. Cuestiona la importancia del Estado en la regulación de la economía, en su papel social y en su función redistribuidora.

El neo-liberalismo económico considera que el Estado no es la solución a los problemas macro-económicos, sino el problema. Es una «carga sin funciones». De ahí la necesidad de reducirlo al mínimo. A dicha reducción debe acompañar, en legítima correspondencia, la reducción de los impuestos que sostienen al Estado, dando como razón la salvaguardia de la libertad individual. A la reducción de impuestos sigue, en la lógica neo-liberal, la negativa a ampliar los servicios públicos, no así la limitación en los gastos de la defensa. Empieza por criticar la ineficacia de las empresas públicas como primer paso para su privatización. Hace una apología de la empresa privada sobre la pública, motivándola en los beneficios y en la eficacia de la gestión.

Uno de los blancos contra quien dirige la crítica es el Estado del bienestar. Dicha crítica se basa en el elevado gasto público que ocasiona y en la amenaza que comporta para la libertad del individuo y la libre iniciativa; ésta se ve limitada, cuando no negada, por el papá-Estado ${ }^{12}$.

Esta concepción insolidaria de la economía desemboca en un darwinismo social inmisericorde, que genera marginación y exclusión social.

La crítica al neo-liberalismo se sustenta en dos principios: $a$ ) el humanismo ético universalista, que defiende el destino universal de los bienes de la tierra - sin discriminación alguna-, a partir de la igualdad de dignidad de todos los seres humanos; b) la propia racionalidad económica, que requiere la intervención de instancias sociales exteriores al mercado en el conflicto de intereses entre los diferentes agentes económicos. Así se evita el triunfo de la razón del más fuerte y la eliminación de los más débiles ${ }^{13}$.

\section{Del individualismo a la disolución del sujeto}

La sociedad moderna caracterizada por el consumismo, la unidimensionalidad y la razón instrumental termina por disolver el sujeto, como ya viera perspicazmente Max Horkheimer: «Es un hecho que nadie puede hoy vivir por sí mismo y que cualquiera (que lo haga) puede ser sospechoso en una sociedad de masas. Cualquier persona necesita una coartada permanente. El individuo... sólo debe estar listo para adaptarse y recibir órdenes» ${ }^{14}$.

${ }^{12+}$ J. K. Galbraith, La cultura de la satisfacción, Madrid, 1992; L. de Sebastián, La gran contradicción del neo-liberalismo moderno, Cristianismo y Justicia/Ayuntamiento de Barcelona, 1989; íd., Mundo rico, mundo pobre, Santander, Sal Terrae, 1992.

${ }^{13}$ Cf. L. de Sebastián, El neoliberalismo. Argumentos a favor y en contra, en VVAA, El neoliberalismo en cuestión, Santander, Sal Terrae, 1993, pp. 27-29.

${ }^{14}$ M. Horkheimer, "The End of Reason», en A. Arato y E. Gebhardt (eds.), The Essential Frankfurt School Reader, Nueva York, Urizen Books, 1977, p. 8. 
El humanismo moderno ha ido perdiendo su identidad y carácter autónomo para, como afirma S. Natole, transformarse en la envoltura de una potencia superior que le controla y domina: la técnica. Ésta, que fue creación del sujeto libre y creador, se ha convertido, a la postre, en su mordaza, en el caldo de cultivo de su propia disolución.

En un clima así, el ser humano vive una experiencia empobrecida, difusa, quebrada, que inevitablemente desemboca en una pobreza antropológica, descrita bellamente por Walter Benjamin con la imagen de la «casa de empeño»: «Nos hemos hecho pobres. Hemos ido entregando una porción tras otra de la herencia de la humanidad, con frecuencia teniendo que dejarla en la casa de empeño por cien veces menos de su valor para que nos adelanten la pequeña moneda de lo actual» ${ }^{15}$. El ser humano vive acelerado en un clima de frivolidad depresiva y va jadeante a uña de caballo tras la presa de lo inmediato, perdiendo una de las dimensiones fundamentales de lo real y de sí mismo: la profundidad.

El ser humano aislado y cerrado sobre sí mismo termina por convertirse en un monstruoso insecto, como el personaje Gregorio Samsa de La metamorfosis, de Kafka. De la razón autosuficiente, única y homogénea de la modernidad se pasa a la quiebra de la estabilidad y de la permanencia del sujeto ${ }^{16}$. «La razón humana - afirma Colli- carece de autonomía, no es más que una resonancia y una manifestación de esa mayor intensidad, es la espuma de una onda expansiva más larga, que luego rompe con más violencia en lo más alto de la escolladera» ${ }^{17}$.

En la década de los sesenta de nuestro siglo, el filósofo francés M. Foucault anunciaba la «muerte del hombre», la disolución de la identidad última del ser humano. El ser humano deja de ocupar el lugar central en que la modernidad le había colocado y deja de ser objeto epistemológico privilegiado. El sueño antropológico de la Ilustración se quedaba en eso, en mero sueño, sin viso alguno de realidad. El ser humano no es el centro de la creación, ni ocupa el punto medio del espacio; no parece encontrarse en la cumbre de la vida. En ese sentido, sentencia Foucault, «la "antropologización" es en nuestros días el gran peligro interior del saber» ${ }^{18}$.

El filósofo francés concluye su iconoclasta reflexión sobre las ciencias humanas con una no menos iconoclasta aseveración contra la centralidad del ser humano: «... una cosa es cierta: que el hombre no es el problema más antiguo ni el más constante que se haya planteado el ser humano. Al tomar una cronología relativamente breve y un corte geográfico restringido - la cultura europea a partir del siglo xvi- puede estarse seguro de que el hombre es una invención reciente. El saber no ha rondado durante lago tiempo y oscuramente

${ }^{15}$ W. Benjamin, Discursos interrumpidos, I, Madrid, Taurus, 1973, p. 173.

${ }^{16}$ Esta idea es desarrollada con lucidez por J. Jiménez, La vida como azar, Madrid, Mondadori, 1989, en el capítulo 9: «Metamorfosis y crisis de identidad», que tengo muy presente y sigo aquí.

${ }^{17}$ Citado por J. Jiménez, op. cit., p. 178.

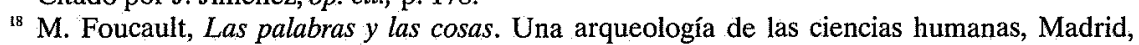
Siglo XXI, 1978, p. 338. 
en torno a él y a sus secretos... El hombre es una invención cuya fecha reciente muestra con toda facilidad la arqueología de nuestro pensamiento. Y quizá también su próximo fin» ${ }^{19}$.

\section{Individualismo postmoderno}

Más que de una nueva ideología, la postmodernidad es un talante de vida, un clima cultural cada vez más extendido, que viene a constatar el fracaso de los grandes ideales de la modernidad y el final de los grandes relatos. La cultura que preconiza es la del fragmento, frente a la de la totalidad del proyecto moderno. No se queda en el ámbito de la reflexión filosófica, sino que tiene su traducción en actitudes y comportamientos vitales concretos.

El clima cultural postmoderno da prioridad a la experiencia sobre el discurso racional, al goce del presente sobre los ideales de futuro, a la singularidad de cada persona sobre la colectividad anónima y la burocracia despersonalizadora, a lo individual sobre lo institucional, a lo personal sobre lo colectivo, al pluralismo sobre el monolitismo, al relativismo sobre el absolutismo, a la tolerancia sobre el dogmatismo. La experiencia se convierte en fuente de saber y aliento para vivir. Hay un protagonismo de los sentidos, de la imaginación y de la intuición.

Una de las actitudes negativas que fomenta el clima postmoderno es el individualismo. La recuperación de la singularidad personal constituye un valor irrenunciable, pero puede desembocar, como de hecho sucede, en egoísmo e insolidaridad. La renuncia a los grandes relatos puede llevar irreversiblemente al olvido de las grandes causas de la justicia, de la libertad, de la igualdad, de la fraternidad-sororidad, y a renunciar a las «causas perdidas» de los pobres y marginados del sistema.

El anclaje en un presente puntual conduce a la pérdida de la memoria histórica y, en consecuencia, al olvido de las víctimas del pasado, cuya rehabilitación no importa. Se corta, así, toda relación con la tradición de los oprimidos, sobre la que se tiende a echar un tupido velo. No hay mirada salvadora dirigida sobre la noche de los vencidos, como dijera Benjamin.

La instalación en un presente inmediato cierra toda posibilidad de mirar hacia el futuro y de colaborar en la construcción de una sociedad venidera más justa y fraterna. El ser humano se queda solo, recluido en su aquí y ahora, sin horizonte histórico, sin utopías ni sueños que den sentido al futuro y animen a recorrer el itinerario humano con la mirada puesta en la meta. No hay motivos para el compromiso.

\footnotetext{
${ }^{19}$ Ibid., p. 375 .
} 


\section{SUBJETIVIDAD Y UTOPÍA}

La dirección de la subjetividad descrita hasta aquí no es la única que ha seguido en el pensamiento moderno, ni la mejor guiada. Hay otra que ofrece perspectivas más prometedoras: la subjetividad abierta a la utopía, al futuro. Ésta ha sido la dirección seguida por el pensamiento utópico desde el renacimiento con la literatura utópica hasta nuestros días con los filósofos y teólogos de la esperanza: Marcel, Bloch, Marcuse, Laín Entralgo, Moltmann.

Ante la imposibilidad de ocuparnos de todas las utopías, nos aproximaremos a algunas de las más importantes desde el Renacimiento hasta nuestros días.

\section{Utopías renacentistas: la cara terrena del cielo}

Las utopías renacentistas son una de las manifestaciones más notorias del giro antropológico del pensamiento y de la cultura a partir del siglo xvi. A través de ellas se abre camino la secularización de la escatología. El cielo pierde su aura trascendente y se torna más humano y más mundano. Las utopías del Renacimiento apuntan a la construcción terrena del paraíso. Algunas de ellas dan a dicha construcción paradisíaca inmanente una cierta carga erótico-ecológica. El cielo es visto como «un lugar de amor erótico en el escenario bucólico de un entorno natural» ${ }^{20}$.

La primera que inaugura el género a principios del siglo Xvi es Utopía, de Tomas Moro. Su modelo utópico de vida no se basa ya en un orden ideal trascendente, sino que tiene su fundamento en la razón y es el resultado de un proceso de racionalización. La razón dicta las nuevas relaciones humanas. La construcción histórica de la utopía no depende de poder divino alguno, sino que es una obra plenamente humana.

Las utopías renancentistas se caracterizan por su función crítica. Son, en palabras de P. Tillich, la «negación de lo negativo». Critican las nuevas estructuras sociales opresivas, la avidez de los propietarios por acumular propiedades. La crítica se centra en la propiedad privada considerada por Moro raíz de los males sociales, causa de la miseria humana y fuente de toda disensión entre los seres humanos. La supresión de la propiedad privada constituye la condición necesaria para una justa distribución de los bienes ${ }^{21}$.

A la crítica sucede la propuesta de una alternativa comunitaria de vida, caracterizada, entre otros rasgos, por la comunidad de bienes y la tolerancia religiosa. En dicha comunidad caben todas las personas sin discriminación alguna. Los problemas se resuelven no recurriendo a las armas, sino por la vía de la concordia.

${ }^{20}$ C. McDannell y B. Lang, Historia del cielo, Madrid, Taurus, 1990, p. 156.

${ }^{21}$ Cf. T. Moro, Utopía (trad., introd. y notas de E. G. Estébanez), Madrid, Zero Zix, 1980. 
Las utopías renacentistas se sustentan en una concepción optimista y esperanzada del ser humano. Muestran su plena confianza en las posibilidades de regeneración ética de la sociedad y en el poder de la ciencia para responder adecuadamente a los problemas del ser humano y de la sociedad en que vive. La obra literaria utópica del Renacimiento que mejor refleja este optimismo hacia la ciencia es la Nueva Atlántida (1627), de F. Bacon, para quien el progreso científico logrará la transformación de las estructuras sociales injustas y desiguales. Bacon se adelanta a Marx en más de dos siglos al considerar la productividad tecnológica como el factor social por excelencia. También $L a$ ciudad del Sol (1623), de Campanella, reconoce la importancia de las ciencias naturales y sus aplicaciones técnicas para el dominio de la naturaleza y la mejora de las condiciones de vida.

Estas utopías contribuyeron a generar entre sus contemporáneos una conciencia crítica, que fue asumida por la modernidad y ha llegado hasta nosotros. De esta manera se superaba la conciencia ingenua e intransitiva, tan arraigada en el mundo eclesiástico y en la cultura medieval.

Sin embargo, cabe preguntarse si dichas utopías salvan la libertad y la independencia del individuo. Hay indicios de que ambas pueden quedar seriamente mermadas. La organización de las comunidades utópicas es tan férrea y perfecta que resulta difícil - por no decir imposible-, el cambio y la disidencia. La perfección parece imponerse por decreto, sin apenas oportunidad de caer en la imperfección. El individuo es objeto de un fuerte control social. La vida comunitaria se rige por normas muy exigentes y restrictivas que regulan la vida entera, desde los comportamientos personales hasta la propia estructura urbanística, desde la forma de vestir hasta los horarios, desde las actividades manuales hasta las inquietudes intelectuales. Se aprecia una cierta tendencia al totalitarismo espiritual y a la uniformidad social. Los habitantes de «Utopía», observa M. Louise Berneri, son «seres uniformes con idénticos deseos y reacciones, privados de emociones y pasiones» ${ }^{22}$. El sujeto corre el peligro de disolverse en una colectividad igualitaria y armónica, pero uniformada e indiferenciada.

\section{Socialismo utópico}

La primera formulación del socialismo moderno asocia a éste con la utopía, dando lugar al llamado socialismo utópico, cuyos principales teóricos fueron Saint-Simon, Fourier y Owen. El socialismo aparece como contrapuesto al individualismo. Así lo presenta Pierre Lerroux en la Revue Encyclopédique (noviembre 1834).

Las consecuencias sociales negativas de la revolución industrial llevaron a los socialistas utópicos a mostrarse críticos con los presupuestos económicos

\footnotetext{
${ }^{22}$ M. Louise Berneri, Joumey through utopie, Londres, 1950, p. 4.
} 
del liberalismo y a plantear la posibilidad de una reforma social y económica que diera lugar a un nuevo modelo de sociedad y de relaciones humanas. Según ellos, el dogma liberal de la libre competencia no logra armonizar los intereses individuales con el interés general, ni ofrece condiciones iguales para todos, sino que genera una desmedida sed de acumulación de bienes y una creciente franja de opresión y exclusión social.

Las fortunas se concentran en muy pocas manos, mientras la miseria afecta a gran parte de la sociedad sometida al proceso de industrialización. A su vez, el desarrollo industrial, no mejora las condiciones laborales y vitales de la clase obrera, sino que tiende a agravarlas en grado sumo. Hay una degradación de la dignidad humana de la clase trabajadora, que, en el caso de las mujeres y de los niños, llega a extremos dantescos.

Los socialistas utópicos proponen alternativas sociales y económicas al modelo industrial vigente. Suelen ser partidarios de la eliminación de la propiedad privada y de la instauración de una sociedad "comunista", según diferentes modalidades. La sociedad comunista propuesta por Owen (1771-1856), acaudalado empresario, es eminentemente agrícola. El utopista inglés comenzó practicando la filantropía patronal con espléndidos resultados tanto en el rendimiento como la producción. Posteriormente recurrió a la ayuda del Estado para alentar su comunismo agrario. Luego promovió un socialismo de carácter mutualista y cooperativo, que no afectaba a la producción.

La crítica que suele hacerse a Owen es que sus experimentos desembocaron en un milenarismo laico con tintes paternalistas. Su doctrina hay que enmarcarla dentro de la ideología burguesa y, en cuanto tal, cuenta con elementos de la tradición utilitarista e idealista, que bien podían ser integrados en la tradición liberal ${ }^{23}$.

Los socialistas utópicos franceses proponen una alternativa no sólo económica, sino de organización social. La teoría de Saint-Simon (1760-1825), aristócrata ilustrado, es una doctrina de la organización de la economía y de la producción que da prioridad a lo económico sobre lo político. La utopía saint-simoniana se centra en el mundo industrial. Busca la reforma social a través de la mejora moral y material dé las clases más desfavorecidas. Hay una significativa sintonía entre Saint-Simon y el marxismo en cuestiones importantes como la crítica de la economía liberal y la importancia de la infraestructura económica. Engels llega a reconocer en el Antidühring la «profundidad genial de mirada» de Saint Simon.

Fourier (1772-1837) coincide con los anteriores socialistas utópicos en su crítica -en este caso, satírica - al sistema capitalista y en la necesidad de crear asociaciones voluntarias. Él se inclina, como Owen, por las asociaciones agrarias. Una de sus principales creaciones es el falansterio, sociedad formada por mil seiscientas personas. No se trata de un sistema comunista, ya que no se elimina la propiedad privada. Reconoce el derecho a la herencia y tiende

${ }^{23}$ Cf. J. Touchard, Historia de las ideas politicas, Madrid, Tecnos, 1970, p. 426. 
a considerar como algo natural tanto la riqueza como la pobreza. A diferencia de Saint-Simon, se muestra contrario a la intervención del Estado en las asociaciones libres.

Marx y Engels se muestran muy críticos con el socialismo utópico y abogan por el paso de éste al socialismo científico, pero no por ello dejan de reconocer sus aportaciones positivas. Los socialistas utópicos descubren el antagonismo entre las clases, pero no llegan a ver en el proletariado «una acción histórica independiente» ${ }^{24}$. Atacan las bases de la sociedad y prestan una importante contribución a la formación de la clase obrera, pero sus doctrinas son «puramente utópicas» ${ }^{25}$.

Marx y Engels critican la pretensión del socialismo utópico de suplantar la acción social por una acción especulativa, las condiciones históricas que han de determinar la emancipación proletaria por condiciones fantásticas, y la gradual organización del proletariado como clase por una organización de la sociedad inventada a su antojo. Llaman la atención críticamente sobre las descripciones fantásticas de la sociedad del futuro que, sin ningún rigor, hace el citado socialismo.

Bloch coincide básicamente con Marx y Engels en la valoración de las utopías de Saint-Simon, Fourier, Owen, Cabet, Proudhon, etc., donde, a su juicio, prima el decreto sobre el análisis científico y la utopía abstracta sobre la concreta. Los socialistas utópicos condenan la injusticias, «pero desde la cabeza» nada más. Las utopías diseñadas tienen su matriz ideológica en el pensamiento racionalista de la burguesía y, como éste, son ahistóricas, no dialécticas, estáticas y doctrinarias ${ }^{26}$. Los utopistas sociales se convirtieron en ingenieros sociales, pero desde la razón pura; sustituyeron una máquina en mal estado por otra que funcionaba perfectamente, pero dejaron intactas las bases del sistema capitalista.

Pero el filósofo de la esperanza no se queda en el lado negativo. Su distanciamiento de los utopistas sociales es sólo parcial. Si bien reconoce que en dichos pensadores hay «un escaso análisis de las tendencias objetivas de la sociedad existente», afirma, al mismo tiempo, en una clara referencia al «marxismo científico», que no se puede caer en la esclavitud de las tendencias objetivas. De ahí su decidido propósito de liberar a la utopía de la «idolatría objetivista de lo objetivamente posible» ${ }^{27}$, que espera la maduración completa de las condiciones económicas para llevar a cabo la revolución. Las condiciones objetivas requieren el concurso de «una voluntad de acción» y de «un sueño anticipador en el factor subjetivo de esta voluntad» ${ }^{28}$. Entra en juego la subjetividad, principio que cuestiona las bases del marxismo ortodoxo y se aproxima al socialismo utópico.

${ }^{24}$ K. Marx y F. Engels, El manifiesto comunista, Madrid, Ayuso, 1976, p. 55.

${ }^{25}$ Ibid., p. 57.

${ }^{26}$ Cf. E. Bloch, El principio esperanza, II, Madrid, Aguilar, 1979, p. 147.

${ }^{27}$ Ibid., p. 148.

${ }^{28} \mathrm{Ibid}$. 


\section{Utopía anarquista}

En la historia de las utopías se suele prestar poca atención a la utopía anarquista. Es verdad que hoy no tiene mucha relevancia social y cultural. Sin embargo, se trata de una utopía que influyó en importantes e influyentes sectores intelectuales y políticos del último tercio del siglo xIX y del primero del siglo xx.

La utopía anarquista apunta derechamente a la destrucción del orden social, político y económico existente y llega hasta el corazón del Estado para destruirlo. Se caracteriza por un amplio pluralismo.

Stirner, por ejemplo, subraya la necesidad de preservar los derechos individuales frente al aplastante y represivo control del exterior, trátese del Estado o de la sociedad. El ideal utópico del ser humano es el propio ser humano individual, cuya soberanía defiende a ultranza. Nada hay que pueda trascenderle o relativizarlo, ni Dios, ni la comunidad. «Yo basaré mi causa en mí: soy como Dios, la negación de todo lo demás, soy para mí Todo, soy el Único» ${ }^{29}$.

Según Proudhon, la justicia está inscrita en el interior del individuo. Asimismo, la justicia social y la igualdad política se encuentran entre las aspiraciones de cada pueblo. La educación constituye el cauce más adecuado para eliminar los obstáculos que se oponen a la justicia y a la equidad.

Bakunin (1814-1876) representa el ala más radical del anarquismo en su versión política. Considera el Estado el mal absoluto y la causa principal de la explotación, de la existencia de las clases y del absolutismo. En consecuencia, aboga por su destrucción como condición necesaria para poder ejercitar la libertad en todos los ámbitos de la existencia: el personal y el colectivo, el económico y el político. De su crítica despiadada al cristianismo se salva la persona de su fundador, Jesús de Nazaret, a quien considera «el predicador del pueblo pobre, el amigo, el consolador de los miserables, de los ignorantes, de los esclavos y de las mujeres» ${ }^{30}$. Reconoce al cristianismo primitivo el mérito de haberse dirigido a la gente doliente, cuyos derechos más elementales eran negados por la aristocracia intelectual y política.

\section{El marxismo: ¿utopía o contra-utopía?}

¿Puede considerarse el marxismo una utopía? Esta pregunta quizá no pudiera hacerse cuando estaba vigente el «socialismo real», por la visceralidad y la falta de equilibrio intelectual reinantes en el ambiente. La respuesta entonces hubiera sido negativa de plano y sin ulteriores distingos o matices. Sin embargo, sí puede hacerse ahora en un clima de reflexión serena, en el que el marxismo no provoca las pasiones, filias y fobias que provocaba en el pasado.

\footnotetext{
${ }^{29}$ M. Stirner, El único y su propiedad, Barcelona, 1974, p. 26.

${ }^{30}$ M. Bakunin, Dios y el Estado, Madrid, Júcar, 1976, p. 120.
} 
Hay que empezar por aclarar que en el marxismo existen diferentes niveles: el filosófico, el ético, el político, el sociológico, el económico, el práxico, el religioso. Aquí no podemos entrar en el desarrollo de cada uno de ellos, ni siquiera analizar si la relación entre ellos es de superposición, complementariedad o contraposición. Lo que sí cabe afirmar es que en los diferentes niveles se explicita una utopía total, que admite diferentes formulaciones: sociedad sin clases, naturalización del ser humano y humanización de la naturaleza, patria de la identidad, etc., que ha sido objeto de diferentes interpretaciones y concreciones históricas.

Ateniéndonos a su historia y a sus manifestaciones teóricas y prácticas, bien puede afirmarse que el marxismo tiene dos caras, como el dios Jano: una que mira hacia adelante y otra hacia atrás. Son la corriente fría y la corriente cálida, según la lúcida tipología de $\mathrm{E}$. Bloch, quien las presenta como complementarias, cuando yo creo que a veces chocan e incluso se contraponen.

Hay un momento en la historia del marxismo en que la corriente fría se convierte en «gélida» y no apunta para nada a la utopía, sino justamente en dirección contraria. Una derivación extrema de la corriente fría es el marxismo ortodoxo, con su materialismo craso, su ateísmo vulgar y su cientismo monista. $\mathrm{Al}$ poner casi exclusivamente el acento en las leyes objetivas de la historia, cierra todo paso a la subjetividad. Contrapone la utopía a la ciencia, dando prioridad a ésta y desestimando la primera.

La traducción política y económica de dicho marxismo es el «socialismo real», que llega a estatalizar no sólo la economía y la política, sino la vida toda, la privada y la pública, la cultura y el saber. Estamos, como veremos más adelante, ante la más roma contra-utopía, que niega la dimensión más irreductiblemente utópica del ser humano, cual es la libertad.

La corriente cálida da lugar al marxismo crítico, humanista y utópico de Bloch, Marcuse, Garaudy y otros, que constituye una de las formulaciones teóricas mejor fundamentadas de la utopía. No contrapone la utopía a la ciencia, como lo hace el marxismo ortodoxo. Lo que hace es establecer una distinción entre utopía abstracta y utopía concreta, abogando por esta última. No cuestiona in toto el socialismo utópico, sino que retoma su herencia críticamente. El marxismo humanista recupera y rehabilita la categoría y el contenido de la utopía, pero no en abstracto, sino en la modalidad de «utopía concreta».

Ahora bien, el hecho de que apunte a la utopía concreta, no quiere decir que se traduzca en unas recetas de aplicación inmediata. La utopía concreta no deja de ser concreta por el hecho de que remita a un ideal tenido por imposible. Lo expresaba diáfanamente Kolakowski en El hombre sin alternativa, donde afirma que la utopía remite siempre a algo que aquí y ahora no es posible. La conciencia anticipatoria de lo que puede y debe ser es uno de los rasgos que definen a la utopía. Y ello frente a la tendencia a anclarse en un presente instalado o en un pasado mítico. Es necesario formular lo que aquí y ahora es imposible como primer paso para que en un futuro sea 
posible. «La existencia de la utopía en cuanto utopía - afirmaba Kolakowski hace seis lustros - es una condición indispensable para que alguna vez deje de serlo» ${ }^{31}$. Hay que tener en cuenta las condiciones objetivas, para no caer en espejismos u optimismos ingenuos, pero también y con la misma intensidad el factor subjetivo, la subjetividad de la acción transformadora. «En el mundo hecho por el hombre - observa Bloch-la propia dialéctica es... una subjetividad que trabaja y que siempre de nuevo rebasa y se esfuerza por romper la objetivación y la objetividad. A fin de cuentas, esa subjetividad es siempre el sujeto menesteroso que se encuentra a sí mismo y a su trabajo objetivado de manera inadecuada; es el animador de las contradicciones que surgen en la historia, el motor intensivo que, bajo los efectos del carácter inadecuado de las formas de existencia alcanzadas cada vez a su propio nivel, se pone en marcha y activa de manera revolucionaria la contradicción que está en la cosa misma y que consiste en la inadecuación entre el contenido subjetivo y la totalidad» ${ }^{32}$.

El marxismo cálido lleva a mirar al futuro con esperanza, pero una esperanza activa, militante, docta, al decir de Bloch, sabedora de las dificultades del camino para el logro de la meta.

La utopía total, y no fragmentaria, del marxismo necesita traducirse en utopía concreta, para no volver a desembocar en utopía totalitaria. Porque de la utopía total a la utopía totalitaria hay un paso. Y el marxismo ortodoxo ya lo ha dado.

\section{La utopia en la reflexión filosófica}

Las utopías tejidas por la humanidad en su historia han sido objeto de una atenta, matizada y crítica reflexión por parte de filósofos, sociólogos y teólogos a lo largo de todo el siglo xx.

La utopía no es un adhesivo externo del sujeto, sino que está inserta en lo más profundo del ser humano, que bien puede ser definido como animal utópico y ser-en-esperanza ${ }^{33}$. La utopía, observa Paul Tillich, «expresa la esencia del hombre, el fin propio de su existencia». En la misma línea se define Ernst Bloch: «El futuro es la cualidad del ser».

La esperanza, en cuanto impulso de la utopía concreta, no es un simple movimiento anímico circunstancial, sino que es constitutiva de la persona («el más importante constitutivo de la existencia humana», matiza Jürgen Moltmann), está radicada en las zonas más profundas del ser humano. Éste es criatura en el tiempo y ser histórico; por ende, sigue el curso de la historia en medio de la oscuridad del presente hasta desembocar en el futuro. El ser humano vive en cuanto espera.

${ }^{31}$ L. Kolakowski, El hombre sin alternativa, Madrid, Alianza, 1970, p. 160.

${ }^{32}$ E. Bloch, Sujeto-Objeto, México, Fondo de Cultura Económica, 1982, pp. 474-475.

${ }^{33}$ He estudiado la antropología en clave de esperanza en J. J. Tamayo, Para comprender la escatología cristiana, Estella, Verbo Divino, 1993, especialmente el capítulo 1 (pp. 19-33). 
La razón que emerge de esta concepción del ser humano es una razón utópica, que no encierra al individuo sobre sí mismo ni le orienta hacia el pasado, sino que está abierta a la comunidad y a la esperanza. La razón utópica cuestiona las estrecheces de la razón instrumental y amplía el mundo (horizonte) de la racionalidad a zonas secuestradas por la concepción cerradamente racionalista de la razón. La razón sin esperanza es ciega y vaga sin rumbo, con peligro de caer en el precipicio. «La razón - dirá aforísticamente Blochno puede florecer sin esperanza ni la esperanza puede hablar sin razón» ${ }^{34}$.

La razón utópica lleva a luchar contra todo derrotismo y contra el optimismo ingenuo, contra el pragmatismo acomodaticio y contra todo intento de programar el futuro.

La filosofía racionalista ha contrapuesto razón y esperanza, pensamiento y utopía, colocando del lado de la razón y del pensamiento los comportamientos lúcidos, el cálculo, la utilidad, la formalización, la ciencia, la técnica, la racionalización, la organización, la mecanización. La utopía y la esperanza se colocan del lado de la irracionalidad, de los impulsos incontrolados, de las reacciones viscerales, de los ciegos instintos.

Quienes más han contribuido a abrir la razón a la utopía en nuestro siglo han sido los filósofos y teólogos de la esperanza. Las aportaciones más relevantes corresponden al filósofo Bloch y al teólogo Moltmann. El primero ha liberado a la utopía de sus connotaciones peyorativas e incluso despectivas y la ha rehabilitado, convirtiéndola en categoría mayor de su filosofía y en el núcleo básico de su antropología.

Bloch se aparta de la interpretación más extendida del marxismo como movimiento teórico y práctico anti-utópico, y lo considera como «ciencia de la esperanza» y como «praxis de la utopía concreta». El marxismo, en su opinión, no sacrifica la utopía por la ciencia, ni opone ésta a aquélla, sino la utopía abstracta a la utopía concreta.

A Bloch le debemos el original descubrimiento de dos corrientes complementarias y mutuamente fecundantes dentro del marxismo: la «corriente fría» y la «corriente cálida» ${ }^{35}$. La primera indaga en las condiciones objetivas de la realidad histórica para fijar una estrategia sensata y precisa; desenmascara las ideologías y desmitifica la apariencia metafísica con que éstas se revisten. La segunda tiene la mirada puesta en la meta, que es la naturalización del ser humano y la humanización de la naturaleza. El filósofo de la esperanza considera necesarias ambas, si bien en toda su filosofía concede prioridad a la «çorriente cálida».

\footnotetext{
${ }^{34}$ E. Bloch, El principio esperanza, III, Madrid, Aguilar, 1980, pp. 491-492. El propio Bloch reitera en otro lugar: «Sólo cuando la razón comienza a hablar, comienza, de nuevo, a florecer la esperanza en la que no hay falsía», El principio esperanza, I, Madrid, Aguilar, 1977, p. 133. He estudiado la filosofía utópica de la religión de Bloch en: Religión, razón y esperanza. El pensamiento de Ernst Bloch, Estella (Navarra), Verbo Divino, 1992.

${ }^{35}$ Cf. E. Bloch, El principio esperanza, I, op. cit., pp. 197-203.
} 
El teólogo alemán Moltmann, siguiendo críticamente a Bloch, redescubre la dimensión utópica del cristianismo. La utopía pertenece a la entraña de la tradición judeo-cristiana. Más aún, es un elemento constitutivo de Dios. El Dios de la tradición bíblica (patriarcas, éxodo, profetas) y cristiana (Jesús de Nazaret, primeras comunidades cristianas, movimientos proféticos) no puede confundirse con el Dios estático, distante, apático y a-histórico de la filosofía griega, sino que es Deus spei, Dios de la esperanza y del futuro. Tal concepción se basa en la religión bíblica de la promesa, que experimenta la realidad como historia en tensión hacia el futuro.

Para Moltmann, la esperanza no es un simple fragmento terminal del pensamiento creyente; constituye un principio teológico; más aún, el principio teológico por excelencia. Ello comporta una modificación fundamental en la concepción del conocimiento teológico: se pasa del anselmiano fides quaerens intellectum al spes quaerens intellectum. La esperanza sostiene a la fe y la impulsa hacia adelante; es resorte del pensar, pero también del actuar, e influye en el pensar y actuar humanos transformándolos. «Resulta imposible -afirma Moltmann - un obrar creador basado en la fe, sin un nuevo pensar y proyectar desde la esperanza» ${ }^{36}$.

\section{La utopía cuestionada}

La razón utópica ha sido objeto de críticas severas por parte de la filosofía y de la teología, de las ciencias sociales y de las ciencias naturales. Una de las más generalizadas es la que echa en cara a la utopía su carácter totalitario y. absolutista tanto en el terreno social como en el epistemológico. Así lo ha puesto de manifiesto Karl Popper ${ }^{37}$, cuya crítica puede resumirse así: quien busca el cielo en la tierra, provoca el infierno en la tierra. La utopía se interesa por el desarrollo de la sociedad en cuanto totalidad. No le importan los aspectos particulares, que se diluyen en el conjunto. El modo de pensar holístico, propio de la epistemología utópica, según Popper, lejos de representar una fase avanzada en la evolución del pensamiento humano, nos retrotrae a una «fase precientífica» y se basa en un grave error metodológico.

Otra crítica apunta a la imposibilidad de realización de los proyectos utópicos y a su falta de realismo. Es la que procede del pensamiento conservador, que no comparte los presupuestos de la filosofía utópica. Al carácter idealista del pensamiento utópico opone un pensamiento «realista». A la política guiada por móviles de trasformación histórica opone una política pragmática y de : respeto al orden establecido.

A la utopía se la considera una secularización de las escatologías religiosas trascendentes. En consecuencia, sus críticos la atribuyen similar grado de fana-

\footnotetext{
${ }^{36}$ J. Moltmann, Teología de la esperanza, Salamanca, Sígueme, 1969, p. 28.

${ }^{37}$ Las obras donde Popper fundamenta su crítica a las utopías son: La miseria del historicismo, Madrid, Alianza, 1973; La sociedad abierta y sus enemigos, Barcelona, Paidós, 1992.
} 
tismo al de las creencias religiosas. Uno de los ejemplos más socorridos al respecto es el utopismo quiliástico de Th. Müntzer, que llevó a los campesinos alemanes revolucionarios hacia una muerte colectiva irremisible.

Hay una última objeción a la utopía: la que la acusa de evadirse de las responsabilidades históricas del aquí y ahora, renunciar al principio de realidad, tenderse en brazos de la imaginación y soñar con islas maravillosas alejadas del mundanal ruido.

Otra crítica es la que procede de la postmodernidad. Más que de una nueva ideología, que haya que situar entre las grandes ideologías de la humanidad, la postmodernidad es un clima cultural, cada vez más extendido, que viene a constatar el fracaso de los grandes ideales y propuestas de la modernidad y el final de los grandes relatos que describían las grandes gestas de la igualdad, de la fraternidad universal, del progreso ilimitado, de la felicidad para todos. La postmodernidad da lugar a una nueva cultura, que es la del fragmento, y a una nueva modalidad de pensamiento, el pensamiento débil. El nuevo discurso postmoderno se caracteriza por su provisionalidad, la parcialidad y la contingencia, ya que tiene su base en la experiencia, y éste posee esos mismos rasgos.

La postmodernidad disuelve el concepto de verdad, renuncia al fundamento, rechaza la filosofía de la sospecha y se opone a toda pretensión totalizadora - considerada totalitaria- de razón. El resultado final de esta concepción deconstructiva es la renuncia a todo intento de formular un proyecto global de transformación de la sociedad y la quiebra de las utopías.

La postmodernidad muestra una faz anti-utópica y niega todo valor a las utopías, apoyándose en dos argumentos. Por una parte, se opone al idealismo y al trascendentalismo que definen a la utopía. «Tomar partido por una conciencia y una sociedad a-utópicas es algo necesario hoy. El fin de la utopía, a fin de cuentas, tiene una virtud incuestionable: nos baja del cielo a la tierra» ${ }^{38}$. La utopía, se dice, no es de este mundo. Por eso se la excluye del mundo de la política, que queda a merced de las soluciones inmediatas, sin horizonte de futuro. Es el día a día lo que impera, más que los proyectos de emancipación a largo plazo. No hay perspectiva histórica.

Por otra parte, la postmodernidad no reconoce un sentido a la historia: «No existe telos alguno de la historia, sino que ésta, al contrario, se presenta coma experiencia repetitiva - a través de mediaciones simbólicas siempre nuevas y con distintos grados de conciencia- de la misma imposibilidad de conciliación» ${ }^{39}$.

${ }^{38}$ M. Porta, «El final de la utopía», El País, 11 de junio de 1986

${ }^{39}$ F. Crespi, «Ausencia de fundamento y proyecto social», en G. Vattimo y P. A. Rovati (eds.), El pensamiento débil, Madrid, Cátedra, 1988, p. 345. 


\section{Rehabilitación crítica de la utopía}

¿Qué actitud adoptar ante las críticas contra la utopía? Creo que deben tenerse en cuenta, valorarlas en sus justos términos, analizar sus fundamentos e identificar los intereses a los que responden.

Hay quienes piensan que la utopía está muerta y bien muerta, y no debe hacerse nada por recuperarla, pues se mueve en el horizonte de los grandes mitos. A este planteamiento cabe responder que la utopía está tan fuertemente enraizada en la realidad y en el ser humano que difícilmente pueda morir.

Otros apuestan por un pensamiento de intención utópica, pero en clave negativa, sin hacer propuestas, sin ofrecer alternativas. La oscuridad del presente, se afirma, no deja otro camino que el de la prohibición de imágenes y la crítica de lo existente. Tal actitud debe ser tenida en cuenta como correctivo a los fáciles discursos afirmativos, pero puede ser paralizante y caer en el pesimismo.

Una tercera actitud, con la que sintonizo, es la rehabilitación crítica de la utopía, es decir, de una utopía no-mitificada, guiada por un interés emancipatorio y animada por una intención ética, en la línea expuesta por J. A. Pérez Tapia, para quien la utopía es necesaria como imagen movilizadora, horizonte orientador de la praxis, instancia crítica de la realidad y eperspectiva para la prospectiva» (P. Ricoeur) ${ }^{40}$. La rehabilitación crítica exige como condición necesaria cuestionar la ingenuidad utópica, que, según F. Hinkelammert, «cubre como un velo la percepción de la realidad social» tanto en el pensamiento burgués... como en el socialista» ${ }^{41}$.

La defensa de la utopía responde a una visión dialéctica y abierta -no determinista- de la realidad. Ha de mantenerse fiel a la intención utópica que la anima, consciente de la distancia entre cómo es el mundo y cómo debe ser, pero con el propósito de aproximar el deber ser al ser. Ha de compaginar adecuadamente la doble dimensión que la caracteriza: crítica y alternativa. Ha de configurarse como utopía cosmo-socio-antropológica; en otras palabras: atender a la interrelación individuo-sociedad-cosmos, sujeto-comunidad-naturaleza, y proponer como meta el logro de la autorrealización personal dentro de la realización de la humanidad y de la liberación de la naturaleza. Debe responder, en fin, a un interés emancipatorio integral no excluyente.

Así entendida, la utopía constituye el horizonte privilegiado en que ha de moverse la acción humana y se convierte en el motor de la historia. Sin ella, la historia vagaría sin rumbo y el ser humano caería en las voraces fauces del destino. La renuncia a la utopía desemboca derechamente en la trivialidad,

\footnotetext{
${ }^{40}$ J. A. Pérez Tapia, Filosofia y crítica de la cultura, Madrid, Trotta, 1995, pp. 96-110.

${ }^{41}$ F. Hinkelammert, Crítica a la razón utópica, 2. ${ }^{2}$ ed., San José (Costa Rica), DEI, 1990, p. 13.
} 
como advierte Jürgen Habermas: «Cuando se secan los manantiales utópicos, se difunde un desierto de trivialidad y perplejidad» ${ }^{42}$.

\section{SUJETO Y COMUNIDAD}

\section{Universalismo jurídico y relaciones dinerarias}

En la primera parte de este estudio veíamos que la miseria del liberalismo radicaba en haberse enrocado en el individualismo y en mostrarse incapaz de generar un tejido comunitario en clave solidaria. El individualismo liberal ha eliminado la comunidad tradicional, al romper los lazos que le servían de cohesión. Pero no ha dejado expedito el camino para construir la comunidad de iguales que propiciaron algunas corrientes utópicas de la modernidad. La burocracia del Estado moderno y el formalismo sistémico han convertido casi en «misión imposible» dicha tarea.

El individualismo se reviste hoy de universalismo jurídico, que, según Pietro Barcellona, «se rige por la reducción de las relaciones interpersonales a relaciones dinerarias» ${ }^{43}$. No hay un reconocimiento personal recíproco, sino «una relación de indiferencia recíproca» (G. Mazzetti). Se respeta la libertad formal, es verdad, pero no la libertad real. Al disolverse las diferentes formas de sociabilidad, no resulta posible la consecución de fines comunes. El universalismo jurídico y la economía dineraria no sólo eliminan toda idea de comunidad, sino que obstaculizan el acceso a una vida individual liberada.

\section{Cristianismo y marxismo: tradiciones comunitarias a recuperar}

Sin embargo, la partida no puede darse por perdida. La creación de la comunidad es necesaria y posible, aunque no está exenta de dificultades. Vamos a recurrir a dos tradiciones, que pueden ayudarnos en dicha reconstrucción: la cristiana y la marxista. Si recurrimos a ellas no es para canonizarlas; ambas dejan mucho que desear dada su práctica anti-comunitaria histórica. Pero en sus núcleos originarios cuentan con una experiencia comunitaria nada desdeñable.

En el cristianismo convergen dos revoluciones culturales: la de la subjetividad y la de la comunidad, que dan lugar a un cambio religioso y cultural importante en el entorno en que se desarrolla y se incultura. El cristianismo se inicia con el movimiento igualitario de seguidores y seguidoras de Jesús, se desarrolla a través de una amplia red de pequeñas comunidades y se propone como alternativa comunitaria de vida frente a las estructuras legalistas del judaísmo.

\footnotetext{
${ }^{42}$ Citado por J. L. Yuste, «Política y utopía», El País, 3 de marzo de 1995, p. 14.

${ }^{43}$ P. Barcellona, Postmodernidad y comunidad, Madrid, Trotta, 1992, p. 112.
} 
El sujeto de la fe en el cristianismo no son las instituciones, ni el Estado; es el yo personal e irrepetible que presta su adhesión a Jesús de Nazaret libremente y hace el camino del seguimiento responsablemente. Pero la fe de la persona cristiana está enraizada en la fe de la comunidad. El yo creyente es sujeto, pero no en cuanto individuo aislado, sino «en su carácter originario subjetivo, en su condición de "hermano"»" ${ }^{44}$. Más aún, la intersubjetividad del acto de fe es «la determinación central» del sujeto cristiano.

En la concepción cristiana del sujeto entra una nueva categoría: la de projimidad. El prójimo constituye el horizonte y el referente de la fe. Una fe no referida al prójimo se queda en la esfera íntima de la persona y tiende fácilmente a convertirse en una especie de auto-consuelo. La salvación en el cristianismo es personal, pero, al mismo tiempo, comunitaria. Si acabamos de decir que el prójimo es horizonte y referente de la fe, ahora damos un paso más y afirmamos que el prójimo es el horizonte y el referente de la salvación cristiana.

Sin embargo, no es comunidad todo lo que reluce en el cristianismo. La fe tiende a recluirse en el ámbito privado de la persona, sin apenas contacto con el exterior. La espiritualidad suele configurarse de manera intimista y aislada del entorno social. La moral cristiana tiende a centrarse en los problemas del individuo. La salvación suele entenderse de manera espiritualista.

Con todo, hoy se están haciendo importantes esfuerzos por devolver al cristianismo su faz comunitaria, y ello no para la propia satisfacción de los cristianos y cristianas. El tejido comunitario constituye un cauce adecuado para reconstruir las alteridades negadas: mujeres discriminadas, clases expoliadas, etnias y razas sojuzgadas, religiones olvidadas. El cristianismo está contribuyendo hoy a redescubrir la riqueza de las culturas pisoteadas, devolver la dignidad negada a las mujeres oprimidas, reconocer la categoría de sujetos históricos a las clases marginadas, recuperar las señas de identidad a las etnias y razas sojuzgadas.

Las comunidades de base y otros movimientos cristianos han sabido captar la vertiente comunitaria del Dios cristiano así como la centralidad de la koinonía ( = comunidad de vida, de fe, de bienes...) en la experiencia cristiana ${ }^{45}$.

Otra aportación nada desdeñable viene de Marx, quien cree que la sociedad de clases elimina a un tiempo la individualidad, porque el ser humano es considerado como objeto y mercancía, y la comunidad, porque los intereses no son comunes, sino contrapuestos. La relación de los seres humanos en el proceso del trabajo no les une en cuanto individuos, sino en cuanto miembros de una clase. He aquí una buena síntesis de la teoría marxista al respecto hecha por Marx y Engels:

«Solamente dentro de la comunidad (con otros) tiene todo individuo los medios necesarios para desarrollar sus dotes en todos los sentidos; solamente

${ }_{44}$ J. B. Metz, La incredulidad como problema teológico, Concilium 6, 1965, p. 77.

${ }^{45}$ He desarrollado esta idea en J. J. Tamayo, Presente y futuro de la teología de la liberación, Madrid, San Pablo, 1994, p. 159. 
dentro de la comunidad es posible, por tanto, la libertad personal. En los sustitutivos de la comunidad que hasta ahora han existido, en el Estado, etc., la libertad personal sólo existió para los individuos desarrollados dentro de la clase dominante y sólo en cuanto eran individuos de esta clase. La aparente comunidad en que se han asociado hasta ahora los individuos ha cobrado siempre una existencia propia e independiente frente a ellos y, por tratarse de la asociación de una clase en contra de otra, no sólo era, al mismo tiempo, una comunidad puramente ilusoria para la clase dominada, sino también una nueva traba. Dentro de la comunidad real verdadera, los individuos adquieren, al mismo tiempo, su libertad al asociarse y por medio de la asociación» ${ }^{46}$.

Sin embargo, la antropología comunitaria de Marx ha sido objeto de todo tipo de perversiones y falseamientos en los regímenes comunistas y se ha convertido en una negación de la persona sometida a la dictadura de la «clase» y en una eliminación de la comunidad sometida al control del «aparato». El intento de instaurar por vía autoritaria $-\mathrm{y}$ muchas veces violenta - la sociedad sin clases ha suprimido la libertad individual y ha impedido la liberación integral de la sociedad. Y, ilo más paradójico!, no logró construir la sociedad sin clases.

Con todo, y tras la crisis del marxismo producida por la caída del socialismo real en los países del Este europeo, hay que volver la vista a la antropología marxista más genuina para recuperar sus componentes emancipatorios de cara al ser humano en su doble vertiente, personal y comunitaria.

\section{Hacia una comunidad racional y de comunicación}

Como alternativa al individualismo liberal, Wolff propone la creación de una comunidad racional basada en el interés público y caracterizada por «una actividad, una experiencia, una reciprocidad de conciencia entre agentes racionales moral y políticamente iguales que libremente se congregan y deliberan, con la finalidad de concertar sus voluntades en la propuesta de objetivos y en la realización de acciones comunes» ${ }^{47}$. Dicha comunidad debe cumplir estos requisitos: el reconocimiento de cada ciudadano como agente moral racional, como sujeto que es fin en sí mismo, y nunca medio para lograr otro fin superior; el reconocimiento de cada persona a la igualdad y a la libertad en diálogo político; la capacidad de réplica sin coacción en el diálogo, en expresión de J. Muguerza, la «concordia discorde» ${ }^{48}$.

Una comunidad así entendida salva tanto a la persona, en cuanto fuente de móralidad, como a la comunidad de personas, movida por objetivos comunes. La persona no se diluye en la comunidad, sino que se siente enriquecida por ella, al tiempo que la comunidad no es el resultado de la suma de unos individuos

\footnotetext{
${ }^{46}$ K. Marx y F. Engels, La ideologia alemana, Barcelona, 1980, p. 86.

${ }^{47}$ R. P. Wolff, The Poverty of Liberalism, Boston, 1968, p. 182.

48 J. Muguerza, op. cit., p. 330.
} 
anexados externamente, sino un grupo de comunicación interhumana con experiencias, intereses e ideales comunes a construir y a compartir.

Habermas propone la construcción de una comunidad de comunicación, donde todas las personas sean interlocutores en la acción comunicativa. Con ello introduce el concepto de «racionalidad comunicativa», que viene a corregir «las reducciones cognitivo-instrumentales que se hacen de la razón» ${ }^{49}$.

R. Mate subraya ecuánimemente la consistencia y las aportaciones de la teoría de la acción comunicativa de Habermas, considerada en amplios sectores como el más logrado y actualizado paradigma de la modernidad. Mate distingue dos tipos de solidaridad y de intersubjetividad: la simétrica o descendente (o por consenso entre iguales) y la asimétrica o descendente, que tiene en cuenta preferentemente los derechos de las personas no-iguales. A este segundo tipo de solidaridad no parece prestarle la debida atención la teoría habermasiana de la acción comunicativa. De ahí que sobre la solidaridad universal de dicha teoría caiga «la sospecha de ser insolidaria en el sentido de que su solidaridad es particular» ${ }^{50}$. Como correctivo a Habermas, Mate habla de la «solidaridad compasiva», que tiene en cuenta de manera prioritaria los intereses de los no-sujetos, no defendidos en la mesa del consenso social.

Coincido con Pietro Barcellona en la necesidad de construir una «nueva comunidad», capaz de compaginar la autonomía y libertad del sujeto, la dimensión social del ser humano y la utopía de una sociedad liberada de las múltiples opresiones que la esclavizan. Dicha comunidad ha de ser fruto de una profundización comunitaria en la democracia y ha de alimentarse en los movimientos sociales. Ninguna de las tradiciones emancipatorias, religiosas o laicas, pueden ser excluidas de este proyecto, tan difícil como necesario e irrenunciable para el futuro de la humanidad.

\footnotetext{
${ }^{49}$ J. Habermas, Teoría de la acción comunicativa, I, Madrid, Taurus, 1987, p. 10.

${ }^{50}$ R. Mate, Mistica y política, Estella, Verbo Divino, 1991, p. 61.
} 